PDFlib PLOP: PDF Linearization, Optimization, Protection

Page inserted by evaluation version www.pdflib.com - sales@pdflib.com 


\title{
Localization and Expression of Osteopontin in Mineralized and Nonmineralized Tissues of the Periodontium ${ }^{a}$
}

\author{
R. L. MacNEIL, ${ }^{b, d}$ J. BERRY, ${ }^{b}$ J. D'ERRICO, ${ }^{b}$ \\ C. STRAYHORN, ${ }^{b}$ AND M. J. SOMERMAN ${ }^{b, c}$ \\ ${ }^{b}$ Department of Periodontics/Prevention and Geriatrics \\ School of Dentistry \\ University of Michigan \\ Ann Arbor, Michigan 48109-1078 \\ 'Department of Pharmacology \\ School of Medicine \\ University of Michigan \\ Ann Arbor, Michigan 48109-1078
}

\section{INTRODUCTION}

A major consequence of periodontal disease is loss of periodontal support, i.e., destruction of supporting periodontal ligament, cementum and bone and subsequently tooth loss if left untreated. The recognition that periodontal regeneration can be achieved, i.e., formation of new bone, new cementum and supportive periodontal ligament, has resulted in increased attempts to understand the mechanisms and factors promoting regeneration. ${ }^{1-4}$ The ultimate goal of these efforts is the development of improved therapies for the treatment of periodontal diseases.

Substantial progress has been made towards understanding the events, factors/ proteins and mechanisms regulating periodontal regeneration. ${ }^{3}$ These advances, coupled with a better appreciation of variables inherent in the host response (e.g., health status, genetics history, behavioral patterns and composite of oral flora), have resulted in improved strategies and, consequently, better clinical outcomes using regenerative therapies. However, current treatment modalities are not predictable and clearly there is a need for increased studies in many areas in order to develop more reliable and efficacious clinical therapies. In order to further our understanding of both the potential and limitation of periodontal regeneration, we established a list of questions to address, with a specific focus on adhesion molecules.

- Can we achieve regeneration predictably?

- What are the timed and spatial events required?

- Does generation recapitulate development?

- What precursor cells/differentiated cells are required?

- What protein/factors are required?

a Source of funding for this study: NIH Grant DE09532.

${ }^{d}$ Corresponding author. 
- Is cementum different from bone?

- Is acellular cementum different from cellular cementum?

Our laboratory has focused on determining the role of adhesion molecules during development, maintenance and regeneration of the periodontium with a major emphasis on adhesion molecules associated with cementum. The rationale for our approach is discussed below and depicted in Figure 1.

\section{HEALTHY, MATURE TOOTH}
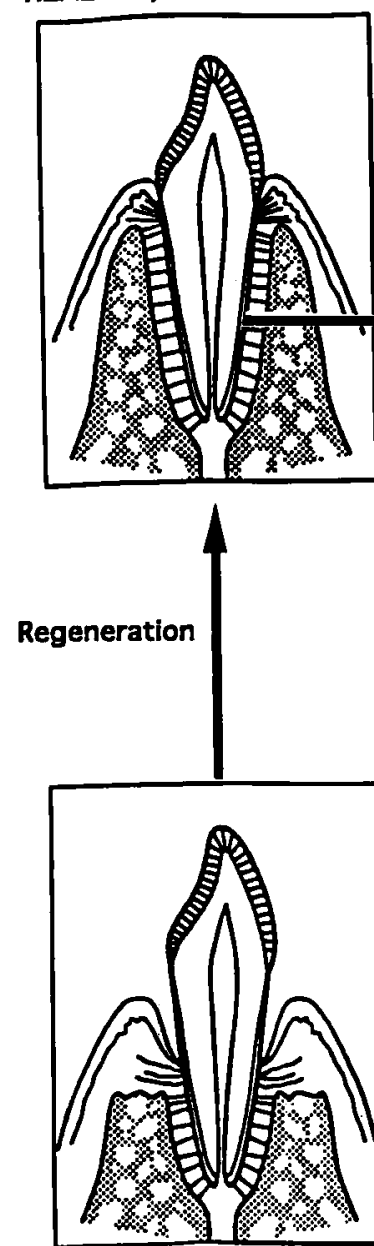

DISEASED STATE
Identify Specific Attachment

Proteins Required to Promote:

A) Development and

B) Regeneration of Periodontal Tissues

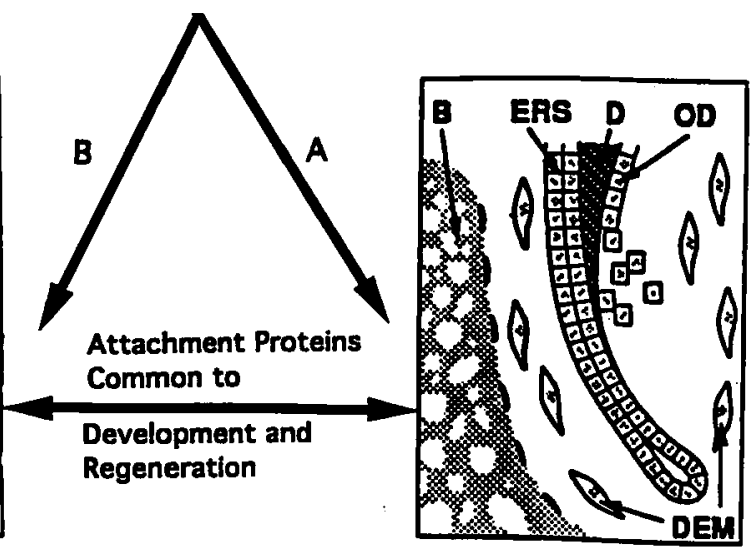

DEVELOPING TOOTH ROOT

FIGURE 1. Rationale for identification of attachment proteins in developing and mature periodontal tissues. 


\section{RATIONALE}

Convincing data, generated from numerous studies, exists supporting the possibility that cell attachment proteins and their corresponding cell surface receptors play a major role in regulating cell differentiation and tissue regeneration in various organ and tissue systems, including the periodontium. ${ }^{5-7}$ Periodontal disease, i.e., periodontitis, results in the lysis and destruction of the fibrous connective tissue attachment which connects tooth root cementum and surrounding alveolar bone. As illustrated in FIGURE 1, this inflammatory process results in a denuded root surface devoid of its supporting tissue, the periodontal ligament (PDL). The concept of periodontal regeneration, i.e., reformation of a new PDL, is based on the premise that surrounding tissues (the remaining PDL, alveolar bone, and other tissues) possess progenitor stem cell populations wth regenerative wound healing potential. To this end, specific surgical debridement techniques have been developed to allow specific cell groups to migrate to and repopulate the root. ${ }^{4,8}$ It is believed that a critical and potentially limiting event in this process is the adhesion of periodontal cells to the root surface. Consequently, clinical attempts have been made to promote cell adhesion to the tooth root using methods such as acid demineralization of the root surface, ${ }^{9-12}$ application of adhesive proteins (e.g., fibronectin) to the root, ${ }^{11}$ and placement of surgical barriers to protect and stabilize the early root-fibrin clot interface. ${ }^{4,13}$ While these approaches have met with some success, the clinical goal of predictable periodontal regeneration has not yet been achieved. A better understanding of the role of adhesion proteins in regenerative wound healing would greatly assist in the development of these therapeutic strategies.

Our investigational approach revolves around two basic concepts: i) the process of cementum formation, i.e., cementogenesis, is the pivotal biologic event in periodontal ligament development; and ii) the molecular processes occurring during developmental and regenerative periodontal tissue formation may be similar (see FIG. 1). In order to determine the role of adhesion molecules in these processes, we first attempted to identify cell attachment proteins in mature cementum. With this information, we then determined the expression of these molecules during cementogenesis. We hypothesize that a precisely timed and spatial expression of specific adhesion molecules is critical to the process of cementum formation and that the identification of the proteins responsible for the promotion of developmental cementogenesis will provide important information regarding regenerative cementum formation.

In order to appreciate the importance of attachment proteins to the process of cementogenesis, a brief review of histological events occurring during cementogenesis is presented below and in FIGURE 1. Depicted in the diagram are the major events occurring in the process of cementogenesis, during molar root formation. In brief, the disruption and migration of cells of the epithelial root sheath (ERS) away from the root surface is timed with the migration and subsequent attachment of cementoblast progenitor cells derived from the ectomesenchyme (i.e., the dental follicle and dental papillae). ${ }^{14-16}$ The attachment of these cells is followed by their differentiation to a cementoblastic phenotype; henceforth, cementoblast cells secrete a collagenous matrix onto the root surface which is then mineralized to form acellular cementum in the coronal half of the root and cellular cementum in the apical half of the root. The specific cellular and extracellular factors which determine the formation of acellular and cellular cementum types remain undefined. Cells of the ectomesenchyme, e.g., follicle and papilla, are thought to be capable, when appropriately triggered, of forming not only cementum, but also 
periodontal ligament (PDL) and bone. ${ }^{14,17,18}$ As previously discussed, we proposed that adhesion molecules are critical for differentiation of these cells and play important regulatory roles in the development of the mature periodontium.

\section{Mature Cementum}

To demonstrate the importance of adhesion molecules during cell differentiation of periodontal tissues we first identified specific adhesion molecules in mature human and bovine cementum. The adhesion molecules identified in mature cementum by our laboratory are listed in FIGURE 1 and include osteopontin (OPN), bone sialoprotein (BSP), vitronectin, and fibronectin. Also included is a partially characterized cementum adhesion molecule (CAP) ${ }^{19-21}$ As a result of these studies, we have determined that cementum may contain unique adhesion molecules, as yet to be fully characterized. ${ }^{22}$

Cementum proteins were extracted from human and bovine teeth by sequential chaotropic extraction using guanidine $(\mathrm{Gu})$ followed by $\mathrm{Gu} / \mathrm{EDTA}$ as reported previously. ${ }^{22}$ The Gu/EDTA extracts of cementum promoted attachment of periodontal cells, e.g., human gingival fibroblasts, human periodontal ligament cells and mouse ectomesenchymal cells. Furthermore, this activity was blocked by arginine-glycine-aspartic acid (RGD) peptides suggesting that RGD-containing ligands must be present in the extract and are responsible, at least in part, for mediating cell attachment. Fractionation of the Gu/EDTA extract by anion exchange, mono $\mathrm{Q}$ column (Pharmacia) attached to a Waters $650 \mathrm{E}$ advanced purification system, resulted in several bands exhibiting attachment activity for mature human periodontal cells. Further studies on these extracts have shown that both bone sialoprotein and fibronectin are found in high concentrations. ${ }^{22}$ Additional known attachment proteins were identified in the Gu/EDTA extract using slot and Western blot analyses. Specific adhesion molecules evaluated included osteopontin, thrombospondin, tenascin, BAG-75 and vitronectin. These studies confirmed the presence of both vitronectin and OPN in cementum. We were unable to identify thrombospondin or BAG-75 in cementum, although these proteins have been identified in bone. ${ }^{23,24}$ However, these studies are preliminary, and additional studies are needed to further clarify the spectrum of adhesion molecules present in mature cementum and to compare their role in cementum versus bone.

With the increasing evidence that two particular bone-associated sialoproteins, OPN and BSP, are involved in the mineralization process, we then focused our attention on the spatial and temporal expression of these two molecules during cementogenesis, using immunological and nucleic acid probes. (For comprehensive reviews on OPN see this volume and Denhardt and Gao (1993), ${ }^{25}$ Patarca et al. (1993); ${ }^{26}$ for reviews on BSP see Fisher et al. (1992), ${ }^{27}$ Sodek et al. (1992) ${ }^{28}$ ) Briefly, OPN, an RGD-containing glycoprotein originally identified in bone is now recognized to be present in many tissues. In bone tissues, OPN has been identified prior to mineralization suggesting a role in regulation of crystal growth ${ }^{29,30}$ In fact, studies are accumulating to suggest OPN may inhibit crystal formation. ${ }^{30-32}$ OPN may also serve a role as i) a chemotactic and attachment factor where OPN has been shown to recruit and stimulate macrophages perhaps as a mechanism for protection against infection, ${ }^{26}$ ii) a modulator of osteoclast function through $\mathrm{Ca}^{+2}$ regulation and control of nitric oxide production, ${ }^{25}$ and iii) an adhesion promoter to regulate matrix-cell and matrix-matrix interactions. ${ }^{33}$ Its possible role in cementum formation is discussed in the next section. In contrast BSP is selective to mineralized tissues and evidence is accumulating that it may have critical role 
as a nucleator of mineralization..$^{29} \mathrm{BSP}$ expression is restricted to bone, cementum, hypertrophic cartilage, with a lesser amount found in dentin, cartilage and decidua.

\section{Cementogenesis}

\section{Materials and Methods}

First molars obtained from CD-1 mice, gestation day 19-60, were initially fixed with several solutions including: $80 \%$ ethanol, $4 \%$ paraform aldehyde and Bouin's solution (Polysciences, Inc. Warrington, PA). We found that Bouin's fixation maintained tissue integrity and was suitable for both immunological and nucleic acid probes. For demineralization of tissues, which was necessary at day 27 , a solution was used containing $10 \%$ acetic acid, $0.85 \mathrm{~g} \mathrm{NaCl} / 100 \mathrm{ml}$ and $4 \%$ formaldehyde. ${ }^{34}$ Tissues were dehydrated and embedded in paraffin. Cut sections, $7 \mu \mathrm{m}$, were placed on 3-aminopropyltriethoxy-silane(TES)-coated slides.

To ensure similar results and reproducible findings, several antibodies for OPN and BSP were used, as well as two staining procedures, fluorescin isothiocyanate conjugate (FITC), and streptavidin alkaline phosphatase conjugate (SAP). Antibodies for BSP provided by Dr. Larry Fisher (NIDR/NIH) included antibodies against human, bovine and rat BSP, all made in rabbit, and all gave similar results in mouse tissues. ${ }^{27} \mathrm{OPN}$ antibodies include $2 \mathrm{arN}^{25}$ (mouse fusion protein antibody) and control cro- $\beta$-galactosidase ${ }^{35}$ provided by Dr. David Denhardt, Rutgers University, bovine OPN antibody prepared by our laboratory and human milk OPN antibody ${ }^{36}$ provided by Dr. Don Senger, Harvard University. OPN antibodies all gave similar results, with $2 \mathrm{arN}$ and milk OPN antibodies having stronger intensities than the bovine antibody. For in situ hybridization, probes used included a mouse BSP cDNA ${ }^{37-39}$ from Dr. Marion Young, NIDR/NIH and two OPN cDNAs-mouse $2 \operatorname{arN}$ cDNA ${ }^{25,35}$ and human OP-10 cDNA, ${ }^{39}$ with similar results. The in situ method used is a modification of Zeller and Rogers (1987). ${ }^{40}$ Both sense (control) and antisense probes were linearized and then ${ }^{35} \mathrm{~S}$-UTP labeled, using the Riboprobe $\$$ Gemini System (Promega Biotec, Madison, WI).

\section{Results and Discussion}

The results of these studies are summarized in TABLE 1. Outlined in TABLE 2 are events occurring at different stages of root development corresponding to the time periods described in TABLE 1 . Results from both in situ hybridization and immunohistochemical studies indicate that BSP localized to and was expressed by alveolar bone and cementum at time points associated with initial mineralization of these tissues. In contrast, OPN was identified in several tissues.

Note: Days reported for rats and mice by other investigators in the following discussion were converted to our numbering system to facilitate comparison of data among different laboratories.

Day 21

Pre root formation; OPN localized to the follicle region (stratum reticulum, stratum intermedium) with intense staining in the region of the gubernaculum. ${ }^{41,42}$ This latter area is considered to be the pathway for tooth eruption. In situ hybridiza- 
TABLE 1. Timed and Spatial Expression/Localization of BSP and OPN during Tooth Root Development ${ }^{a}$

\begin{tabular}{|c|c|c|c|c|c|c|}
\hline \multirow[b]{2}{*}{ Day } & \multirow{2}{*}{$\begin{array}{l}\text { Cells/ } \\
\text { Region }\end{array}$} & \multicolumn{2}{|c|}{ Immunocytochemistry } & \multicolumn{3}{|c|}{ In situ Hybridization } \\
\hline & & BSP & OPN & BSP & OPN & COL1 \\
\hline \multirow[t]{3}{*}{ Day 21} & OD & $+1-$ & $+1-$ & - & $+1-$ & +++ \\
\hline & OST & ++ & + & ++ & ++ & ++ \\
\hline & SR/SI & - & $+t+$ & - & - & - \\
\hline \multirow[t]{3}{*}{ Day 27} & OD & - & ++ & - & $+1-$ & +++ \\
\hline & OST & ++ & $+1-$ & ++ & ++ & ++ \\
\hline & RS & ++ & - & - & - & - \\
\hline \multirow[t]{4}{*}{ Day 42} & OD & - & $+1-$ & - & $+1-$ & +++ \\
\hline & OST & ++ & $+1-$ & ++ & ++ & + \\
\hline & RS & ++ & + & ++ & ++ & ++ \\
\hline & PDL & - & $++t$ & - & +++ & +++ \\
\hline
\end{tabular}

a Abbreviations: COL1, collagen type I; OD, odontoblasts; OST, osteoblasts; SR/SI, stratum reticulum/stratum intermediate; RS, root surface; PDL, periodontal ligament.

tion revealed intense positive bone cells, in the area of eruption. It is noteworthy that OPN was localized in the pathway of tooth eruption where bone resorptive activity must occur to allow for the eruptive movement of the tooth. OPN is thought to be an adhesion molecule for osteoclasts, ${ }^{43}$ although its absence from the sealing zone of osteoclasts as reported by Lakkakorpi et al. (1991) ${ }^{44}$ has led to some question as to the exact function of OPN in regulation of osteoclast behavior. OPN did not stain (or weakly stained) odontoblasts at this stage, and this is in agreement with studies on day 20-22-rats by Helder et al. $(1993)^{45}$ and Mark et al. (1988). ${ }^{46}$ Chen et al. (1993) reported OPN staining for odontoblasts and odontoblast processes, but not peritubular dentin in day 35/50 porcine fetuses. ${ }^{47}$ Our in situ hybridization studies indicated weak/no expression for OPN by odontoblasts with a positive response in osteoblasts (TABLE 1).

At day 21 BSP localization/expression was limited to surrounding alveolar bone. A very weak stain for BSP was noted in the odontoblast region, but in situ hybridization indicated that odontoblasts at this developmental stage do not express BSP. In contrast, Chen et al. (1992) reported BSP expression in odontoblasts of day-21 rats. ${ }^{48}$

TABLE 2. Tooth Development in Mice ${ }^{a}$

\begin{tabular}{ll}
\hline Age & \multicolumn{1}{c}{ Stage of Tooth Development } \\
\hline 10 & tooth development/bone initiated \\
11 & dental lamina-odontogenesis \\
$11-25$ & enamel/dentin crown formation \\
$25-27$ & disruption of Hertwig's root sheath \\
$27-40$ & acellular cementum formation, physiologic tooth eruption \\
$40-60$ & cellular cementum formation, root partially formed \\
110 & fully formed roots
\end{tabular}

${ }^{a}$ This aging is based on vaginal plug date $=$ day 0 . Note: mice are usually born on day 19. By day 35 eruption of molars into the oral cavity can be seen. 


\section{Day 27}

At this stage, dentinogenesis at the root region is noted, the ERS begins to disintegrate and cementogenesis is initiated.

With initiation of root formation OPN was localized to ERS at the area of newly forming root and also noted in the odontoblast region. In situ hybridization studies indicated a weak response for odontoblasts. Surrounding bone cells and matrix were positive for OPN. This is in agreement with Bronckers $e t$ al., who report that OPN was localized to cellular, acellular cementum, PDL, bone, and odontoblasts in day-34/59 rat molars. ${ }^{49}$

At this same time point, BSP was expressed and localized to the region of primary deposition of extracellular matrix onto root dentin. Staining was also noted in surrounding bone. Immunostaining in the dental papilla was close to background. In porcine molars, day-35/50 fetuses, Chen et al. (1993) reported positive staining for odontoblasts, but weak expression by in situ hybridization. ${ }^{47}$

\section{Day 42}

At this stage in mice, first molars are in early phases of eruption into the oral cavity and root formation is well advanced but incomplete.

At day 42, strong staining for OPN was noted at the cementum surface and throughout the PDL. Dental papillae did not stain strongly. In situ hybridization suggested a similar pattern of expression, strong in cells throughout the PDL and the root surface with weak or no expression noted in odontoblasts.

For the most part these findings are in agreement with other studies. The description here of strong localization/expression of OPN in the PDL contrasted to weak expression in odontoblasts is both supported and challenged by previous studies. OPN has been identified in the PDL by Takano-Yamamoto et al. $(1994)^{50}$ using approximate day-68 rat molars and in situ hybridization (digoxigenin RNA probes) and by Bronckers et al. (1994) ${ }^{49}$ using rat molars at 34 and 59 days and immunolocalization. Conversely, McKee and Nanci (1994) noted only weak staining for OPN in acellular cementum and cellular cementum and an absence of OPN in the PDL proper using a rat model ${ }^{33}$ Even more uncertainty exists whether OPN is expressed by odontoblasts at latter stages of tooth development. Takano-Yamamoto et al. (1994), using in situ hybridization, did not observe expression of OPN by rat odontoblasts at day $68 ;^{50}$ this finding contrasts with immunohistochemical data reported here and by others (Bronckers et al., 1994) which suggests that odontoblasts express OPN. ${ }^{49}$ The fact that OPN has been biochemically identified in mature dentin, ${ }^{51}$ albeit to a lesser degree than in bone, and immunolocalized in mantle dentin, ${ }^{33,49}$ indirectly suggests that odontoblasts synthesize OPN. Hence the inability to confirm the localization/expression of OPN in odontoblasts may be largely due to the limits of the specific techniques employed. Future studies, using a variety of probes, different species and freshly isolated mRNA cell preparations may help to resolve this ongoing controversy.

BSP localization and expression was distinct at this stage of root development. BSP localized to the root surface starting at the CEJ and continued along the root surface to its apical terminus. Surrounding bone also stained for BSP. Cells lining the root surface associated with both cellular and acellular cementum expressed BSP. This expression was restricted to cells lining the root surface and also to cells lining the surrounding bone. Cells within the PDL were not positive for BSP. 


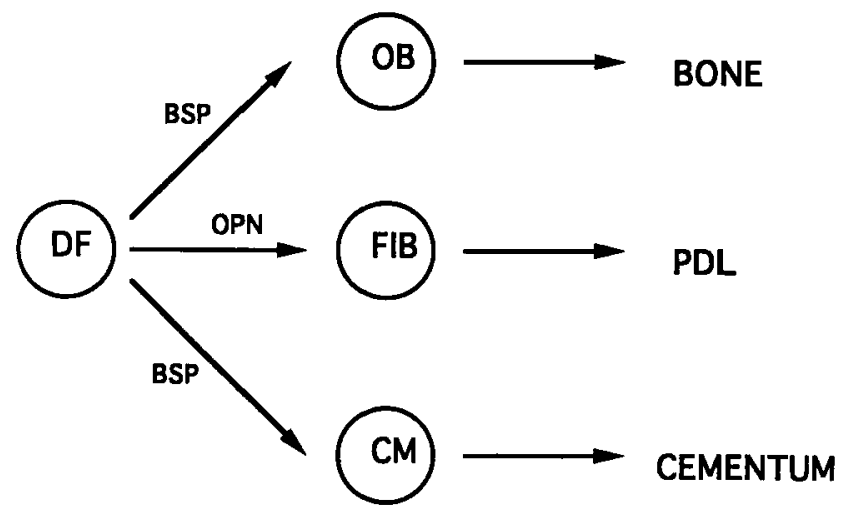

FIGURE 2. Proposed pathways for differentiation of periodontal tissues. Abbreviations: DF, dental follicle; OB, osteoblast; FIB, fibroblast; CM, cementoblast; BSP, bone sialoprotein; OPN, osteopontin.

These findings are in agreement with Chen et al. $(1992)^{48}$ where they reported BSP expression by rat cementoblasts, day 80 .

\section{SUMMARY}

To summarize results from various studies focusing on determining the expression/localization of BSP and OPN during tooth root development, there is general agreement that OPN is expressed/localized to the root surface during cementogenesis and is also seen throughout the PDL region. The expression/localization of OPN to odontoblasts and its role in dentinogenesis is less apparent. Recent studies directed at establishing odontoblast cell lines should help to resolve this conflict.

Studies on BSP expression during tooth root formation indicate a very precise expression and localization of this molecule during cementogenesis indicating that this molecule may play an important role in the formation of this mineralized tissue. ${ }^{52}$ However, as with OPN, the expression of BSP and its role in dentin formation is not clearly defined.

\section{FUTURE DIRECTIONS}

The studies outlined here demonstrate clearly that BSP is expressed in a highly specific fashion during root molar development consistent with the spatial and temporal initiation of cementogenesis. Most recently, we reported that RNA isolated from day-27 follicle cells express BSP mRNA. Thus we predict that BSP secretion onto the root surface is required for normal development of cementum and that follicle cells in the local environment, when triggered appropriately, are the cells which express and secrete BSP onto the root surface. Alternatively OPN may allow normal periodontal ligament alignment, by controlling the rate of root mineralization, thus preventing ankylosis (FIG. 2). Furthermore, the timed and 
spatial expression of specific surface receptors on cells during molar development is required for controlling migration and attachment of cementoblast progenitor cells onto the root surface. We consider these events/factors, critical for initiating cementogenesis and for maintaining a functional periodontium. Future studies are directed at establishing that BSP and follicle cells are responsible for inducing cementum formation and that OPN is important as a modulator of periodontal ligament function.

\section{REFERENCES}

1. Aukhil, I., K. Nishimura \& W. Fernyhough. 1990. Experimental regeneration of the periodontium. Crit. Rev. Oral Biol. Med. 1: 101-105.

2. CAfFesse, R. G. \& C. R. Quinones. 1993. Polypeptide growth factors and attachment proteins in periodontal wound healing and regeneration. J. Periodontol. 2000 1: 69-79.

3. McCulloch, C. A. G. 1993. Basic considerations in periodontal wound healing to achieve regeneration. J. Periodontol. 2000 1: 16-25.

4. O'Neal, R., H-L. Wang, R. L. MacNeil \& M. J. Somerman. 1994. Cells and materials involved in guided tissue regeneration. Cur. Opin. Periodontol. 1994: 141-156.

5. Albelda, S. M. \& C. A. Buck. 1990. Integrins and other cell adhesion molecules. FASEB J. 4: $2868-2880$.

6. HYNES, R. D. 1992. Integrins: versatility, modulation, and signaling of cell adhesion. Cell 69: 11-25.

7. MARIOTTE, A. 1993. The extracellular matrix of the periodontium: dynamic and interactive tissues. J. Periodontol. 2000 3: 39-63.

8. Becker, W., B. Becker, L. Berg, J. Prichard, R. Caffesse \& E. Rosenberg. 1988. New attachment after treatment with root isolation procedures: class III and class II furcations and vertical osseous defects. Int. J. Periodontal Res. Dent. 8: 9-23.

9. Caffesse, R. G., C. E. Nasjleti, G. B. Anderson, D. E. Lopatin, B. A. Smith \& E. C. Morrison. 1991. Periodontal healing following guided tissue regeneration with citric acid and fibronectin application. J. Periodontol. 62: 21-29.

10. Handelsman, M., M. Davarpanah \& R. Celletti. 1991. Guided tissue regeneration with and without citric acid treatment in vertical osseous defects. Int. J. Periodontal. Res. Dent. 11: 350-363.

11. Kersten, B. G., A. D. Chamberlain, S. Khorsandi, U. M. Wikesjo, K. A. Selvig \& R. E. NiLveus. 1992. Healing of the intrabony periodontal lesion following root conditioning with citric acid and wound closure including an expanded PTFE membrane. J. Periodontol. 63: 876-882.

12. Parashis, A. O. \& F. J. Mitsis. 1993. Clinical evaluation of the effect of tetracycline root preparation on guided tissue regeneration in the treatment of class 11 furcation defects. J. Periodontol. 64: 133-136.

13. Wikesjo, U. M. E. \& R. Nilveus. 1990. Periodontol repair in dogs: effect of wound stabilization on healing. J. Periodontol. 61: 719-724.

14. Ten Cate, A. R., C. Mills \& G. Solomon. 1971. The development of the periodontium: a transplantation and autoradiographic study. Anat. Rec. 170: 365-380.

15. CHо, M-I. \& P. R. GARANT. 1988. Ultrastructural evidence of directed cell migration during initial cementoblast differentiation. J. Periodontal. Res. 23: 268-276.

16. Thomas, H. F. \& E. J. Kollar. 1988. Tissue interactions in normal murine root development. In The Biological Mechanisms of Tooth Eruption and Root Resorption. Z. Davidovitch, Ed. 107-116. EBSCO Media. Birmingham, AL.

17. PALMer, R. M. \& A. S. Lumsden. 1987. Development of periodontal ligament and alveolar bone in homografted recombinations of enamel organs and papillary, pulpal and follicular mesenchyme in the mouse. Arch. Oral Biol. 32: 281-289.

18. Osborn, J. W. \& D. G. PrICE. 1988. An autoradiographic study of periodontal development in the mouse. J. Dent. Res. 67: 455-461. 
19. Mcallister, B., A. S. Narayanan, Y. Miki \& R. C. Page. 1990. Isolation of a fibroblast attachment factor from cementum. J. Periodontal Res. 25: 99-105.

20. Arzate, H., S. W. Olson, R. C. Page, A. M. Gown \& A. S. Narayanan. 1992. Production of a monoclonal antibody to an attachment protein derived from human cementum. FASEB J, 6: 2990-2995.

21. Pitaru, S., N. Savion, H. Hekmati, S. Olson \& S. A. Narayanan. 1993. Molecular and cellular interactions of a cementum attachment protein with periodontal cells and cementum matrix components. J. Periodont. Res. 28: 560-572.

22. Somerman, M. J., J. J. Sauk, R. A. Foster, K. Dickerson, K. Norris \& W. S. ARgRaves. 1991. Cell attachment activity of cementum: bone sialoprotein II identified in cementum. J. Periodontal. Res. 26: 10-16.

23. Robey, P. G., M. F. Young, L. W. Fisher \& T. D. MCClain. 1989. Thrombospondin is an osteoblast-derived component of mineralized extracellular matrix. J. Cell Biol. 108: 719-727.

24. Sato, M., W. Grasser, S. Harm, C. Fullenkamp \& J. P. Gorski. 1992. Bone acidic glycoprotein 75 inhibits resorption activity of isolated rat and chicken osteoclasts. FASEB J. 6: 2966-2976.

25. DenhaRd, D. T. \& X. Gao. 1993. Osteopontin: a protein with diverse functions. FASEB J. 7: 1475-1482.

26. Patarca, R., R. A. Saavedra \& H. Cantor. 1993. Molecular and cellular basis of genetic resistance to bacterial infection: the role of the early T-lymphocyte activation-1/osteopontin gene. Crit. Rev. Immunol. 13: 225-246.

27. FiSHER, L. W. 1992. Structure/function studies of the sialoglycoproteins and proteoglycans of bone. It is still the early days. In Chemistry and Biology of Mineralized Tissues. H. Slavkin \& P. Price, Eds. 177-187. Excerpta Medica. AmsterdamNew York.

28. Sodek, J., J. Chen, S. Kasugai, T. Nagata, Q. Zhang, M. D. McKee \& A. NANCI. 1992. Elucidating the functions of bone sialoprotein and osteopontin in bone formation. In Chemistry and Biology of Mineralized Tissues. H. Slavkin \& P. Price, Eds. 297-307. Excerpta Medica. Amsterdam-New York.

29. Hunter, G. K. \& H. A. Goldberg. 1994. Modulation of crystal formation by bone phosphoproteins: role of glutamic acid-rich sequences in the nucleation of hydroxyapatite by bone sialoprotein. Biochem. J. 302. In press.

30. Hunter, G. K., C. L. Kyle \& H. A. GoldberG. 1994b. Modulation of crystal formation by bone phosphoproteins: structural specificity of the osteopontin-mediated inhibition of hydroxyapatite formation. Biochem. J. 300: 723-728.

31. Shiraga, H., W. Min, W. J. VanDusen, M. D. Clayman, D. Miner, C. H. Terrell, J. R. Sherbotie, J. W. Foreman, C. Przysiecki, E. G. Neilson \& J. R. Hoyer. 1992. Inhibition of calcium oxalate crystal growth in vitro by uropontin: another member of the aspartic acid-rich protein superfamily. Proc. Natl. Acad. Sci. USA 89: $426-430$.

32. Boskey, A. L., M. Maresca, W. Ullrich, S. B. Doty, W. T. Butler \& C. W. PRINCE. 1993. Osteopontin-hydroxyapatite interactions in vitro: inhibition of hydroxyapatite formation and growth in a gelatin-gel. Bone Miner. 22: 147-159.

33. MCKeE, M. D. \& A. NANCI. 1994. Osteopontin at mineralized tissue interfaces in bone, teeth and osseointegrated implants: ultrastructural distribution and implications for mineralized tissue formation, turnover and repair. Microsc. Res. Tech. In press.

34. D'Souza, R. N., R. P. Happonen, N. M. Ritter \& W. T. Butler. 1990. Temporal and spatial patterns of transforming growth factor- $\beta_{1}$ expression in developing rat molars. Arch. Oral. Biol. 35: 957-965.

35. Craig, A. M., M. Nemir, B. B. Mikherjee, A. F. Chambers \& D. T. Denhardt. 1988. Identification of the major phosphoprotein secreted by many rodent cell lines as 2ar/osteopontin: enhanced expression in H-Ras transformed 3T3 cells. Biochem. Biophys. Res. Commun. 157: 166-173.

36. Senger, D. R., C. A. Perruzzi, A. Papadopoulos \& D. G. Tenen. 1989. Purification of a human milk protein closely similar to tumor-secreted phosphoproteins and osteopontin. Biochem. Biophys. Acta 996: 43-48. 
37. Fisher, L. W., O. W. McBride, J. D. Termine \& M. F. Young. 1990. Human bone sialoprotein: deduced protein sequence and chromosomal localization. J. Biol. Chem. 265: 2347-2351.

38. Young, M. F., J. M. Kerr, K. Ibaraki, P. Dominguez, L. W. Fisher \& P. G. ROBEY. 1992a. Unusual DNA structures within the bone sialoprotein and osteonectin genes are potential candidates for transcriptional control. In Chemistry and Biology of Mineralized Tissues. H. Slavkin \& P. Price, Eds. 243-252. Excerpta Medica. Amsterdam-New York.

39. Young, M. F., J. M. Kerr, J. D. Termine, U. M. Wewer, M. G. Wang, O. W. MCBRIDE \& L. W. FISHER. 1992b. cDNA cloning, mRNA distribution and heterogeneity, chromosomal location, and RFLP analysis of human osteopontin (OPN). Genomics 7: 491-502.

40. Zeller, R. \& M. Roger. 1987. In situ hybridization and immunocytochemistry. In Current Protocols in Molecular Biology. F. M. Ausubel, R. Brent, R. E. Kingston, D. D. Moore, J. G. Seldman, J. A. Smith \& K. Struhlk, Eds. 14.0.1-14.6.13. Greene Publishing Associates \& John Wiley and Sons. New York.

41. Somerman, M. J., B. Shroff, W. S. Argraves, G. Morrison, A. M. Craig, D. T. DenHardT, R. A. Foster \& J. J. Sauk. 1990. Expression of attachment proteins during cementogenesis. J. Biol. Buccale. 18: 207-214.

42. Somerman, M. J., B. Shroff, R. A. Foster, W. T. Butler \& J. J. Sauk. 1992. Mineral-associated adhesion proteins are linked to root formation. Proc. Fin. Dent. Soc. 88(Suppl. I): 451-462.

43. Reinholt, F. P., K. Hultenby, A. Oldberg \& D. Heinegård. 1990. Osteopontin-a possible anchor of osteoclasts to bone. Proc. Natl. Acad. Sci. USA 87: 4473-4475.

44. Lakkakorpi, P. T., M. A. Horton, M. H. Helfrich, E-K. Karhukorpi \& H. K. VÄÄNÄNEN. 1991. Vitronectin receptor has a role in bone resorption but does not mediate tight sealing zone attachment of osteoclasts to the bone surface. J. Cell Biol. 115: 1179-1186.

45. Helder, M. N., A. L. J. J. Bronckers \& J. H. M. Woltgens. 1993. Dissimilar expression patterns for the extracellular matrix proteins osteopontin (OPN) and collagen type 1 in dental tissues and alveolar bone of the neonatal rat. Matrix 13: 415-425.

46. Mark, M. P., W. T. Butler, C. W. Prince, R. D. Findelman \& J-V. Ruch. 1988. Developmental expression of 44-kDa bone phosphoprotein (osteopontin) and bone $\gamma$-carboxyglutamic acid (Gla)-containing protein (osteocalcin) in calcifying tissues of rat. Differentiation 37: 123-136.

47. Chen, J., C. A. G. MCCulloch \& J. Sodek. 1993. Bone sialoprotein in developing porcine dental tissues: cellular expression and comparison of tissue localization with osteopontin and osteonectin. Arch. Oral Biol. 38: 241-249.

48. Chen, J., H. S. Shapiro \& J. Sodek. 1992. Developmental expression of bone sialoprotein mRNA in rat mineralized connective tissues. J. Bone Miner. Res. 7: 987-997.

49. Bronckers, A. L. J. J., M. C. Farach-Carson, E. V. Waveren \& W. T. Butler. 1994. Immunolocalization of osteopontin, osteocalcin, and dentin sialoprotein during dental root formation and early cementogenesis in the rat. J. Bone Miner. Res. 9: 833-841.

50. Takano-Yamamoto, T., T. Takemura, Y. Kitamura \& S. Nomura. 1994. Sitespecific expression of mRNAs for osteonectin, osteocalcin, and osteopontin revealed by in situ hybridization in rat periodontal ligament during physiological tooth movement. J. Histochem. Cytochem. 42: 885-896.

51. Fujisawa, R., W. T. Butler, J. L. Brunn, H. Y. Zhov \& Y. Kuboki. 1993. Differences in composition of cell-attachment sialoproteins between dentin and bone. $J$. Dent. Res. 72: 1222-1226.

52. MacNeil, R. L., N. Sheng, C. Strayhorn, L. W. Fisher \& M. J. Somerman. 1994. Bone sialoprotein is localized to the root surface during cementogenesis. J. Bone Miner. Res. 9: 1597-1606. 